\title{
Where constructionism and critical realism converge: interrogating the domain of epistemological relativism
}

Article

Accepted Version

Al-Amoudi, I. and Willmott, H. (2011) Where constructionism and critical realism converge: interrogating the domain of epistemological relativism. Organization Studies, 32 (1). pp. 27-46. ISSN 1741-3044 doi:

https://doi.org/10.1177/0170840610394293 Available at https://centaur.reading.ac.uk/24956/

It is advisable to refer to the publisher's version if you intend to cite from the work. See Guidance on citing.

To link to this article DOI: http://dx.doi.org/10.1177/0170840610394293

Publisher: Sage

All outputs in CentAUR are protected by Intellectual Property Rights law, including copyright law. Copyright and IPR is retained by the creators or other copyright holders. Terms and conditions for use of this material are defined in the End User Agreement.

www.reading.ac.uk/centaur 
Central Archive at the University of Reading

Reading's research outputs online 
Where Constructionism and Critical Realism Converge: Interrogating the Domain of Epistemological Relativism ${ }^{\mathrm{i}}$

Unedited version of a paper published in

Organization Studies, January 2011 32: $27-46$

for correct quotations please see the original publication in Organization Studies

Ismael Al-Amoudi

University of Reading

i.alamoudi@reading.ac.uk

Hugh Willmott

University of Cardiff

willmotth@cardiff.ac.uk

13 December 2011

Word count: 11,142 words 


\begin{abstract}
The paper interrogates the status, nature and significance of epistemological relativism as a key element of constructionism and critical realism. It finds that epistemological relativism is espoused by authorities in critical realism and marginalised or displaced in the field of management and organisation studies, resulting in forms of analysis that are empirically, but not fully critically, realist. This evaluation prompts reflection on the question of whether, how and with what implications, epistemological relativism might be recast at the heart of critical realist studies of management and organisation.
\end{abstract}

Keywords: Critical realism, constructionism, epistemology, methodology, paradigms, relativism, ontology.

\title{
Introduction
}

'Realism' and 'constructionism, ${ }^{\text {,i }}$ have emerged as broad categories and as antinomies for labelling forms of analysis and ascribing theoretical allegiances. Dialogue between their respective affiliates has, however, been muted; and this limitation has been compounded by each 'rendering themselves intelligible' in opposition to, rather than engagement with, the other (Gergen 1998: 153). An outcome has been a solidifying of realism/constructionism as a ‘bi-polar hierarchy' (Van Maanen 1995). Scholarship located and positioned on one or other side of the divide in a way has tended to cult-ivate and justify a disinclination to give careful consideration to the other's claims (see for instance Edwards, Ashmore et al. 1995). 
A widely held view is that realist and constructionist positions are divided inter alia on epistemology, with relativism being the province of constructionists. This understanding is, however, difficult to reconcile with statements from leading advocates of critical realism (CR) who have stressed the centrality of epistemological relativism. Lawson (2003b), for example, writes:

'I do accept the relativity of knowledge. I do not suppose for a moment that social ontology or anything else could be represented or produced in other than a manner that is conditioned by our socio-cultural (or biological or physical) determinations. This is precisely what lies behind my acceptance of an epistemological relativism...within the realist project (and perhaps more widely...)'

Lawson continues:

'[epistemological relativism] expresses the idea that our categories, frameworks of thinking, modes of analysis, ways of seeing things, habits of thought, dispositions of every kind, motivating concerns, interests, values and so forth, are affected by our life paths and sociocultural situations and thereby make a difference in how we can and do "see" or know or approach things, and indeed they bear on which we seek to know' (ibid: 162, emphasis added)

If, as this passage suggests, critical realism incorporates epistemological relativism, a number of questions are begged that are of direct relevance to students of management and organization studies, including: 
1) What place does epistemological relativism ${ }^{\text {iii }}$ occupy in the formulation of critical realism $(\mathrm{CR})$ ?

2) How is CR, including its espousal of epistemological relativism, disseminated and translated into the field of management and organization studies (MOS)?

3) What are the implications of embracing epistemological relativism fully for the identity of CR and its application to MOS?

To address these questions, we begin by outlining our understanding of CR before surveying its presence in MOS. We then review a number of empirical studies that claim a CR pedigree prior to evaluating the extent to which epistemological relativism is incorporated into such analyses. These reflections lead us to consider whether, and how, epistemological relativism might be recast at the heart of $\mathrm{CR}$, and the possible implications of such recasting for CR contributions to MOS. Our polyphonic response to this issue comprises a sceptical and an optimistic assessment. The sceptical assessment identifies epistemological relativism as an anomalous element whose closer engagement threatens to destabilise CR and precipitate a shift to some alternative form of analysis. The optimistic stance entertains the possibility of epistemological relativism being more fully appreciated, recovered and incorporated within CR analysis so as to facilitate its strengthening and extension.

\section{Our understanding of $C R$}

Prior to outlining key features of CR, we briefly explicate our own stance. We attend to $\mathrm{CR}$ as a discourse - that is, as a structured system of differential positions that has a 4 
'material character' and confers meaning to its elements (Laclau and Mouffe 1985: pp. 105$108)^{\mathrm{iv}}$. This stance may alarm those who (mistakenly, in our view) conflate interest in discourse with idealism, or with the analysis of texts abstracted from their constitutive embeddedness in the materiality of social relations. This (mis)understanding may be applicable to some forms of discourse theory and analysis but, as Laclau explains in a debate with Bhaskar, a principle architect of $\mathrm{CR}$, a conception of discourse 'could, if you prefer, be replaced by that of practice' (Bhaskar and Laclau 2002: 81). And when elaborating his conception of discourse theory with which we are broadly sympathetic, Laclau explicitly states that 'the main philosophical approach that [discourse theory] is opposed to is idealism'. This conception of discourse theory, which 'sustains the irreducibility of the real to discourse' (Bhaskar and Laclau 2002: 81), is also, we suggest, broadly but incompletely consistent with the realist position advanced by Bhaskar (1998b: 16) for whom the activities, theories and philosophies of science, in which we understand CR to be included, are conceived as 'artificial objects'. Such activities, theories and philosophies are artificial objects in the sense that they are constructed out of available 'facts and theories, paradigms and models, methods and techniques of enquiry available to a particular scientific school or worker' (Bhaskar 1998b: 16) We say that agreement on this point is 'incomplete' as we assess CR, and especially its engagement in the field of MOS, to be susceptible to forgetfulness of its own subscription to, and advocacy of, epistemological relativism.

Having sketched our position on CR, we now outline what we regard as CR's key features. In doing so, we acknowledge the impossibility of presenting an authoritative, unitary and definitive account of CR. Our response to this difficulty is (i) to acknowledge CR's status as an ongoing programme; and (ii) to portray those features that are shared by proponents of $\mathrm{CR}$ who are widely regarded, from within and without $\mathrm{CR}$, as authorities on the subject. Amongst them are Margaret Archer, Roy Bhaskar, Andrew Collier, Tony Lawson 5 
and Alan Norrie who collectively edited Critical Realism: Essential Readings (1998). We take this volume, together with a number of Bhaskar's texts as 'authoritative' in respect of CR.

The Transitive-Intransitive Distinction. A fundamental characteristic of the CR project is its insistence upon establishing and 'sustain[ing] a clear concept of the reality of being - of the intransitive or ontological dimension - in the face of the relativity of knowledge - in the transitive or epistemological dimension' (Bhaskar 1998a: x, text modified). CR articulates and defends a 'logics of reference' (Bhaskar in Bhaskar and Laclau 2002) in which knowledge has two dimensions: one transitive, artificial, dimension constituted by the concepts we use as references to the world; the other, intransitive and constituted by the world qua referent. CR pays particular attention to what it identifies as confusions of these dimensions. Accordingly, the interpretation of statements about being as statements about knowledge of being is characterised as an epistemic fallacy (Bhaskar 1986: 6); and the obverse 'reduction of knowledge to being' (Bhaskar 1986: 23) is referred to as an ontic fallacy.

The idea of an 'intransitive dimension of knowledge' is especially prone to miscomprehension and confusion. Consider a drink served to Sally. If Sally thinks of a cold drink, she relies on and re/produces language and concepts (the transitive objects of knowledge) through which she refers to her drink (the intransitive object of knowledge). The key distinction in CR between transitive and intransitive is between reference and referent and not - as the terms in/transitive may suggest - a distinction between mutable and immutable features of reality (cf. infra for a discussion). Sally's drink (the intransitive object of Sally's knowledge) may become warmer or colder just as the meaning invested in the concept of a 'drink' (the transitive object of Sally's knowledge) may change over time. 
Moreover, CR holds that the transitive dimension forms part of the intransitive dimension. Knowledge does not exist in a separate world: the transitive is differentiated from, but not exterior to, the intransitive. So, if Bobby were to study what Sally thinks of her drink, then her thoughts and the language/knowledge she relies on would constitute Bobby's intransitive objects of knowledge. In this case, the transitive objects of Bobby's knowledge would comprise the knowledge and theories (sociological or otherwise) through which he understands Sally's sense-making.

Generative Mechanisms. With specific reference to the development of scientific knowledge, the abstractions which comprise explanations are understood to have their 'grounds... in the real stratification (and ontological depth) of nature and society' (Bhaskar 1998a: xvi). Such abstractions, Bhaskar contends, ' '... are not subjective classifications of an undifferentiated empirical reality' (Bhaskar 1998a: xvi), but, rather, are 'attempts to grasp... precisely the generative mechanisms and causal powers which account in all their complex and multiple determinations for the concrete phenomena of human history' (Bhaskar 1998a:Xvi). Generative mechanisms are located within CR's stratified, depth ontology where the intransitive dimension (see above) is conceived to comprise three domains (Bhaskar 1978; see also Fleetwood 2005): (i) the empirical which is that of experience (e.g. Sally's perception of cold); (ii) the actual which is one of events as well as experiences (e.g. Sally's drink burning her lips); and (iii)the real which includes mechanisms in addition to experiences and events (e.g. the molecular structure of Sally's drink that makes it prone to slow changes in temperature). Generative mechanisms are conceived to be "real and distinct from the patterns of events that they generate; just as events are real and distinct from the experiences in which they are apprehended" (Bhaskar 1998b: 41). It is these generative mechanisms, according to $\mathrm{CR}$, that are retroduced in the course of scientific study of the 
natural and social worlds, and subsequently subjected to empirical scrutiny and rational judgement vis à vis the claims of competing explanations.

Judgmental Rationality. Distinguishing the dimension of ontology from that of epistemology (see above) is essential, advocates of CR argue, if there are to be shared reference points for making rational judgements between alternative theories. Failure to uphold this distinction is seen to 'render problematic the idea of a rational choice between "incommensurable" theories and to encourage (superidealist) scepticism about the existence of a theory-independent world' (Bhaskar 1998a: x-xi). Alternative theories and explanations are not just different as a consequence of their suppositions. As "incommensurable" theories' about 'the same world' (Bhaskar 1998a: x-xi), they are understood to compete and conflict in their claims to advance upon established explanations.

Epistemological Relativism. The process of retroductive judgement by which generative mechanisms are identified is understood to be mediated by historically and culturally partial processes of interrogation. For instance, in different epochs, Sally would more likely attribute the gradual cooling of her drink to the weakening of the element of fire, or to the transfer of kinetic energy, or to particle vibrations. The criteria employed for preferring one explanation rather than another is, at least in part, dependent on the historicocultural community in which debates about competing claims are staged (Roy Bhaskar, personal communication). Retroductive judgments provide possible but historically contingent explanations of certain states of affairs. Their apparently compelling "necessity" is, then, more congruent with what Kant terms "problematic" rather than "apodictic" judgments. It is relevant to underscore how epistemological relativism means more than mere fallibilism (i.e. the assumption that every form of knowledge is open to error). It is not only a matter of every knowledge being potentially 'wrong' but also, and most crucially, a matter of 
knowledge being historically transient (a product of our position, perspective, histories), and of acquiring its meaningfulness and value relative to the time, place, and position of the knower (see Bhaskar 1989: 19). Had Sally lived in the times of Parmenides, she would have lacked the conceptual framework to refer to heat as 'kinetic energy' or 'particle vibrations'. Nonetheless, the framework familiar to her would have enabled Sally to defend an elemental theory of heat at least as convincingly as most people living in the $21^{\text {st }}$ Century.

\section{Discussion}

Two understandings of the transitive-intransitive distinction seem to cohabit in the CR literature. One understanding interprets the intransitive as the realm of the immutable objects of the natural world that exist independently of human activity and the transitive as the historically transient realm of human activity. In this interpretation, 'transitive' and 'intransitive' refer to two ontologically distinct realms of reality. This understanding is shared by commentators such as Burkitt (1999), King (1999a; 1999b) and Newton (2007). For instance, Burkitt suggests that:

'in the distinction between transitive and intransitive [Bhaskar] has separated out what appear to be two distinct realms and, despite his own best intentions, divided the ontological realm from the social. That is, reality appears to be governed by its own laws in some independent realm that is distinct from humans, and transformational activity seems confined only to the social-epistemic' (Burkitt 1999: 73).

This interpretation of the transitive-intransitive distinction is partly justified by Bhaskar's (Bhaskar 1978) analysis of the activity of natural scientists: 
'Our knowledge is 'of' things which are not produced by men at all: the specific gravity of mercury, the process of electrolysis, the mechanism of light propagation. None of these 'objects of knowledge' depend upon human activity. If men ceased to exist, sound would continue to travel and heavy bodies would fall to the earth in exactly the same way, though ex hypothesi there would be no-one to know it. Let us call these, in an unavoidable technical neologism, the intransitive objects of knowledge'. (Bhaskar 1978: 21)

It is worth remarking, however, that Bhaskar insists elsewhere that social structures are both intransitive (Bhaskar 1998/1979: 47) and dependent on people's conceptions of what they are doing in their activity (Bhaskar 1998/1979: 38). In doing so, how is Bhaskar postulating an antinomy of CR, as claimed by King (1999b) and other critics?

Another understanding - that we favour (cf. supra) - interprets the distinction between transitive and intransitive as a distinction between reference (which is by definition knowledge) and referent (which may or may not be knowledge). In this interpretation, the transitive is nested in the intransitive and agents' concepts are constitutive, though not exhaustive, of the social. The social is not assumed to exist independently of human activities.

At the same time, Bhaskar nonetheless distinguishes CR from idealism by maintaining that the act of scientific discovery does not create ipso facto the intransitive object of discovery, be it social or natural. As he puts it

\footnotetext{
'Note that to affirm the distinct identity of thought and intransitive object, or of the epistemic 2 and the ontic 2 , is not to deny, but on the contrary
} 
presupposes not just that thought is (ontologically2) part of being, but also the possibility of causal relations between the being of a knowledge and the distinct being of its object - in both the cognitive and conative 'directions of fit'. This holds both in particular cases, e.g. in the causal efficacy of an object in the process of its cognition (e.g. in experiment) and in the possible reciprocal efficacy of knowledge, once achieved, on its object (e.g. in the mining of a mineral, once its presence has been detected); and as between knowledge and being generally, e.g. in emergence and technology respectively' (Bhaskar 1986: 53, n.92)

To return to our example of Sally's drinking habits, Bobby may discover that she has a preference for lukewarm coffee. This discovery presupposes that Sally's preference (the intransitive object of Bobby's knowledge) pre-existed Bobby's (transitive) knowledge. It may also be argued, in turn, that Bobby's discovery, when known by Sally, is likely to influence her future preferences. In response to his quizzical reaction, she may start to drink, and in time prefer, hot coffee, in line with contemporary, socially sanctioned, taste. Yet, the transformation of Sally's taste is not instantaneous. If Sally is influenced by Bobby's assessment, the transformation occurs in the future and is mediated through processes (e.g. Sally subsequent interpretation and so on) that are irreducible to Bobby's knowledge.

Our understanding of the transitive-intransitive distinction is shared by leading CR authorities, including Archer (2000), Lawson (1998) and Sayer (2000: 10). Thus, Archer (2000: 465) specifies in a response to King (1999a) that the dualism is analytical, not philosophical: (intransitive) structures are only held to emerge from the activities of people 
and conversely structures only exert any effect when mediated through the (transitive) activities of people. Similarly, Lawson suggests that:

'because social structure is existentially dependent upon human agency (as well as vice versa) the procedures of social science are likely to differ in various ways from those of natural science. However, it does not follow from this that social structures are other than intransitive. To describe certain objects or features as intransitive is merely to indicate that they exist at least in part independently of any knowledge claims of which they are the referents. Thus intransitive objects of knowledge need be no more fixed or enduring than transitive ones. If I am studying the thought of a second person, for example, her or his thought constitutes an intransitive object of my enquiry.' (Lawson 1998).

As we turn from the writings of $\mathrm{CR}$ authorities to consider examples of avowedly CR analysis in MOS, it is remarkable how little attention is paid to the (central) transitiveintransitive distinction upon which CR's combination of ontological realism and epistemological relativism is based. This silence prompts reflection upon the translation and dissemination of CR into MOS.

\section{The Dissemination of CR into Management and Organization Studies}

A number of researchers in MOS have identified CR as a promising approach (see for instance Mutch, Delbridge et al. 2006). Indeed, according to Reed (2005b - see also 
Fleetwood and Ackroyd 2004a; 2005a), CR has been gaining momentum to the point of inspiring a "realist turn". To this turn, he attributes the following characteristics. First, the turn "provide(s) an overarching explanatory framework and logic" for substantive research on organisations (Reed 2005b: 1637). Second, it aspires to gain access to a "deeper level of social and organizational reality, not readily available to direct observation or description..." (Reed 2005b: 1639). These characteristics chime with our earlier account of the first and second of CR's four key elements and also, potentially, to the discriminating powers of judgemental rationality. Reed also suggests that CR is open to multiple research methods as it "does not legitimate or license any particular substantive theoretical perspective or body of social theorising" (Reed 2005b: 1637-1638). As will become clear, we are not fully persuaded that CR can readily accommodate diverse research methods or bodies of social theorizing; or, at least, it seems to us that the requirements associated with key elements of CR place limits on their scope.

Finally, Reed positions CR in opposition to all forms of postmodernism and poststructuralism (typically of Foucauldian inspiration); and he counters these with CR-informed approaches, such as critical discourse analysis (e.g. Fairclough 1995; Fairclough, Jessop et al. 2002). As our focus upon epistemological relativism perhaps implies, we question the plausibility of positioning $\mathrm{CR}$ in diametric opposition to all forms of poststructuralism. In our assessment, leading advocates of CR (e.g. Bhaskar) and at least some forms of poststructuralist analysis (e.g. Laclau's social theory of hegemony) share an acceptance of the contextual, theorydependence of knowledge production, and an associated rejection of the dogmatic (empirically realist) assumption that such dependence can be eliminated by methodological diversity, eclecticism or virtuosity. Our attentiveness to CR's espousal of epistemological relativism is intended, in part, to excavate the basis of our reservations about how CR has 
been characterized and positioned by those (e.g. Reed, Fleetwood, Fairclough) who advocate it as a promising approach within MOS.

Debating CR in MOS

Dialogue between advocates of 'realism' and 'constructionism', as distinct from petty sniping, has been limited across the social sciences (see Parker 1998 for a partial exception). In MOS, the most cited example is an exchange between Mir and Watson (2000; 2001) and Kwan and Tsang (2001) (but see also exchanges between Reed 2005a; 2005b and Contu and Willmott 2005; and between Tsoukas, 1994 and Willmott 1996). Mir and Watson (2001) claim a 'constructivist' monopoly on sensitivity to theory dependence. This is challenged by Kwan and Tsang (2001) who point out that this sensitivity is incorporated within critical realism, in contrast to forms of 'dogmatic realism' that ignore this theory dependence or conceive of it as a source of bias amenable to progressive elimination. $\mathrm{CR}$ is distinguished by Kwan and Tsang (2001) from what they describe as a more 'radical' stance in which the theoretical stance of the researcher is conceived to 'determine research such that 'reality has no input to and control over scientific findings'. The latter, 'constructivist' view, they contend, 'quickly leads to epistemological relativism' (Kwan and Tsang 2001: 1164-1165, emphasis added). This positioning and assessment of CR is at once confusing and revealing. Along with other advocates and defenders of CR within MOS, Kwan and Tsang erroneously conceive of CR's distinctiveness in terms of its rejection of epistemological relativism. As we have seen, however, epistemological relativism is a central plank of the CR credo. In effect, Kwan and Tsang conflate 'epistemological relativism' with 'epistemic fallacy' (cf supra). 
Appreciating the centrality of epistemological relativism for CR, we contend, is of critical importance for enabling CR, as a 'philosophical underlabourer' (Mutch 2007), to guide scholarly activities undertaken in its name.

Epistemological relativism: lost in dissemination

In the process of its adoption within management and organization studies (MOS), the centrality of epistemological relativism within CR has apparently been forgotten. To explore the dissemination of $\mathrm{CR}$ into MOS, we focus upon the contributions to Ackroyd and Fleetwood (2000) and Fleetwood and Ackroyd (2004). The rationale for concentrating on these texts is that they were selected by the editors as illustrative, or as exemplary, of CRinfused contributions to MOS. The stratagem, we believe, offers a firmer basis for evaluation than, say, an examination of a random selection of articles from the population of 136 pieces published between 1990-2006 (see Appendix). Had we adopted the latter approach, we could, quite justifiably, have been criticised for analysing papers that, for whatever reason, include the term 'critical realism' in the title, abstract or key words but are assessed to be tangentially CR in inspiration or application. These concerns also inform our decision to adopt Fleetwood and Ackroyd's distinction between 'three areas in which CR ideas have been found of particular relevance to organization and management studies' (Fleetwood and Ackroyd 2004: 4). These three areas are:

1) the meta-theory of management and organization studies which is distinct from substantive social scientific theorising but may inspire substantive theories and indicat[e] likely sources of bias and error' (Fleetwood and Ackroyd 2004: 4); 
2) the methodology of MOS in which category are placed contributions to the two collections that reflect on the appropriateness of specific research methods to their subject matters; and

\section{3) Examples of new substantive social science research written from a critical realist point of} view that are illustrative of the payoff of adopting a CR perspective for MOS researchers. (Fleetwood and Ackroyd 2004: 5).

When examining the contents of the Fleetwood and Ackroyd (2000; 2004) collections, we found that epistemological relativism occupies a visible but subordinate position in meta-theory papers and then almost vanishes in the more substantive contributions. To the best of our knowledge, the most complete account of CR's epistemological relativism in MOS scholarship appears in Fleetwood's (2004) contribution. which underscores how CR understands that knowledge of the social world is inescapably mediated by available conceptual resources:

'There is no theory-neutral observation, description, interpretation, theorisation, explanation, or whatever. There is, in other words, no unmediated access to the world: access is always mediated. Whenever we reflect upon an entity, our sense data is always mediated by a preexisting stock of conceptual resources which we use to interpret, make sense of and understand what it is, and take appropriate action... (Fleetwood 2004: 30).

It is evident from this passage that, in Fleetwood's assessment, the metatheoretical explication of $\mathrm{CR}$ incorporates an understanding that forms of observation, interpretation and 
explanation are mediated by theory. Whether this extends beyond fallibilism is unclear but, as emphasised earlier, CR authorities conceive of processes of interrogation and adjudication as incorrigibly culturally mediated, and not simply methodologically imperfect. To what extent, then, is the espoused centrality of epistemological relativism in CR recognised and engaged in the contributions to the Ackroyd and Fleetwood (2000) and Fleetwood and Ackroyd (2004) collections? If, as we endeavour to demonstrate, it is barely recognised or not incorporated, then the significance and implications of the oversight merit some consideration. With regard to the "substantive" contributions to these collections, our assessment is based on chapters authored by Delbridge; Taylor and Bain; Kowalczyk and Kennedy; Hesketh and Brown (in Fleetwood and Ackroyd 2004) and by Coopey et al; Costello; Easton and Porter ${ }^{\mathrm{v}}$ (in Ackroyd and Fleetwood 2000). With the partial exception of Porter's chapter, none of these contributions directly attends to epistemological relativism or, more specifically, acknowledges and engages with the fallibility or relativity of the claims made therein.

What can we expect from the application of an approach whose authorities avowedly give as much weight to epistemological relativism as to ontological realism and judgemental rationality? Our response is that, at the very least, CR analysis should incorporate and/or exemplify some minimal appreciation of how there is no unmediated access to reality. That is to say, CR studies in MOS can be expected to attend to how the' pre-existing stock of conceptual resources' (Fleetwood 2004) contributes to delimit the otherwise indeterminate meaning of the issues, analyses and solutions articulated by researcher and participants. What do we find? Porter (2000: 145) valuably acknowledges that 'While it is important to realise that "the social world may be opaque to the social agents upon whom it depends" 
(Bhaskar 1989a: 4), distinguishing between clarity and opacity is problematic, given that analysts themselves cannot have direct contact with the reality of social structures.' This is a promising start. It is disappointing that the remainder of Porter's chapter lacks sensitivity to how concept dependency implies more than a mere acknowledgement of fallibility. It incorporates no consideration of how concepts are framed, re/produced and transformed. At most, Porter portrays agents who are faced with the task of 'collapsing structural variables into categories that can inform interactional practices ... Thus, in a social situation where nurses deemed open expressions of racism as inappropriate, they filtered them out, selecting instead professional modes of interaction.' (Porter 2000: 156-157). In the other chapters of the edited collections, the categories used by contributors - such as 'workers', 'managers', 'employers', 'employees', 'team', ‘workplace', 'merger', 'humour', 'hospital', 'nurses', and so on - are taken for granted, naturalised and unquestionably assumed to provide adequate respresentations of their referents. The reluctance to 'defactualize' these categories is highly problematical for analyses that are presented as exemplars of CR. This denial or disregard of CR's epistemological relativism is, we suggest, illustrative of the kind of (empirical realist) mode of analysis lampooned by Bhaskar (1986: 284) as taking 'a dozy bask in the retrojected glories of earlier objectifications of thoughts, misconstrued as natural givens'. It is to the unintended consequences of the 'naturalisation' of these categories in MOS scholarship that our attention now turns.

\section{Implications for substantive CR studies in MOS}


We have argued that the significance of epistemological relativism is not reducible to fallibilism; and that an adequate understanding of epistemological relativism requires an appreciation of how the categories used by researchers are inherently artificial objects (see Bhaskar 1978, especially p. 249). An implication of this conjecture is a call for closer attentiveness to the naturalisation of categories used in the practices of participants (see Sayer 2005). Otherwise, studies become indistinguishable from empirical realist, and more specifically structuralist, forms of analysis where categories are routinely naturalized.

In structuralism, categories used to codify observations are defined a priori and are assumed to be relevant in all observed settings (Dreyfus and Rabinow 1982: xix-xx). Contra structuralism, CR and poststructuralism share a rejection of the view that conceptual elements should be identified independently of the situation under scrutiny (1982: 54-56). Porter's analysis (cf. Supra) exemplifies a structuralist approach insofar as she interprets social situations in reference to categories that are implicitly assumed to be relevant and meaningful independently of context: white vs ethnic minority; nurses vs. doctors; overt racism vs. covert racism, competent professional vs. incompetent professional. Porter's analysis includes little to counteract the impression that racist relations, attitudes and behaviours, for example, are self-perpetuating and have an autonomy of their own - an omission that, unfortunately, gives succour to the objection, as voiced by Burkitt (1999), King (1999a; 1999b) and Newton (2007), that in CR writings reality appears to be disconnected from human sense-making activities (cf. supra). Our contention is that CR's commitment to epistemological relativism is disruptive of structuralist and empirical realist analysis. In principle, CR's commitment to epistemological relativism problematises the universality or acontextuality of the categories upon which it relies. Analyses incorporating 'epistemological relativism' can accept that the categories of 'white', 'doctor' and 'competent', for example, are pragmatically useful and that they purport to reference certain aspects of existing states of affairs. But critical realist 19 
analysis which delivers on its commitment to epistemological relativism cannot, in our view, entertain any suggestion that (i) these categories provide the way of, say, categorising hospital staff and/or (ii) presume that the categories are a priori preferable to other categorisations (eg. friendly/unfriendly, nice looking/ugly, religious/a-religious, and so on). In sum, incorporating a commitment to epistemological relativism encourages reflection upon the formation of, and relation between, categories in accounts of social situations; and there is a questioning of any suggestion that these categories are universal or that they can be understood independently of the contexts of their use (see Bhaskar, 1986, especially p 280 et $\operatorname{seq})$.

Attentiveness to CR's epistemological relativism suggests a direction for critical realist studies that incorporates awareness of how categories used by participants, as well as those employed by the researcher, obtain their positivity, grip or charge from a particular order of discourse (Foucault 1970; Edward and Willmott 2008). "Doctor" and "nurse", for instance, are not meaningful because they refer to "real doctors" or to "real nurses" but because they are performed within a hegemonic set of discursive practices (the discourse of the hospital). Participation in these practices fosters recognition or, indeed, compels privileged use of these categories and confers a positivity upon them. Our point is that in order to be consistent with a commitment to epistemological relativism, the dependence of meaningful concepts on discursive orders could, and arguably should, be fully acknowledged and incorporated into CR analysis.

This proposal requires proponents of CR analysis to pay more than lip service to the understanding that elements of discourse deployed to reference objects of study are not neutral. It means, for example, being attentive to how an interaction that is represented as taking place between a "doctor" and a "nurse" (that is, being framed within a discourse of the 
hospital) may alternatively be interpreted as an interaction between, say, a "woman" and a "man" (e.g. when framed within a feminist discourse). As (ontological) realists, critical analysts are obliged to appreciate how the meaningfulness of claims is dependent upon particular discourse(s) in which their statements are articulated (Bhaskar 1986: 98-102). Appeals to "the doctor" or "the man" may be directed to the same person; yet the meanings conveyed or performed, as well as the conceptual frameworks mobilized, differ significantly, as may the consequences flowing from their operation. It is for this reason that constructs used by participants should not be invoked simply as available (categorical) resources to be used in critical realist analysis. Instead, in CR studies, the constructs of critical realist analysis become interrogated as topics of de-naturalized analyses. Such critical analysis might, for example, include examination of the practices that sustain the hegemony of established forms of categorization in a hospital (e.g. nurses vs doctors, medical decisions vs administrative decisions, and so on.)

Critical Realism and Poststructuralism

The affinity between the analytical implications of CR's commitment to epistemological relativism and aspects of postructuralist thinking is apparent inter alia in the interpretive analytics developed by Foucault (Foucault 1972; Foucault 1977; Foucault 1978, see also Al-Amoudi 2007, Joseph 2004 and Marsden 1999). We consider three aspects of the formation of agents' categories of interpretation. First, there is the system of differentiations through which (transitive) objects of knowledge are constituted and which permit some people to act upon the actions of others (eg. 'doctor / patient' though not 'im-moral madness / ir-rational madness' in contemporary hospitals). Second, there are the enunciative modalities that describe and determine 'who can make what claim?' (e.g., who can diagnose a disease? 21 
Who can decide to lock up a patient? Which patients are entitled to discuss the various treatments available to them?). Third, there is the apparatus (dispositif) constituted by the related verbal practices and their relations to non-verbal practices and entities. Verbal practices directly involved in, and constitutive of, a doctor/patient relationship include questioning the patient, billing medical fees, negotiating possible treatments, and so on. Nonverbal practices and entities ${ }^{\mathrm{vi}}$ include touching and manipulating the patient's body, using operation rooms, uniforms, surgical tools, email systems and so on. This list is far from exhaustive. Its purpose is to illustrate how Foucaultian analytics, for example, have relevance for studying the transitive dimension of agency and the latter's wider social effects. Such enquiries into these systems of differentiation, enunciative modalities and dispositifs are intended to describe and to explain. They seek to retrace the typically overlooked links between the meanings on which agents rely in their routine activities and the relations of power through which they interact. That kind of analysis has not, to our knowledge, been advocated or advanced by proponents of CR, perhaps as a consequence of a tendency, noted earlier, to polarize critical realism and constructionism. Yet, such analysis could, we believe, offer a powerful corrective to structuralist and empiricist tendencies that we detect in ostensibly CR studies within MOS.

In addition to stressing how concepts acquire their meaningfulness from the discourses through which they are articulated, we have also hinted at how discourses, far from being innocent or neutral, articulate relations of power. Unquestioning reproduction of the categories used by participants tends to make researchers complicit in the perpetuation of the practices and internal relations associated with the categories. For this reason, a full engagement of epistemological relativism has political implications for research. Problematising the categories is subversive as it shows the limits of the signifier's capacity to signify its signified, and the capacity of the reference to express its referent. 'Worker' and 
'manager', for example, are simultaneously present in a variety of discourses, each of which delimit the boundaries for these categories (see Laclau and Mouffe 1985: 126-127). The different meanings of "manager" found in textbooks, workplaces, consultancy firms and other institutions, suggest the possibility of challenging dominant meanings by developing alternative (critical) discourses for investing words, such as 'manager', with meaning, and for transforming their meaning in specific settings and/or of subverting their use. That this is possible is evident in the widespread contemporary appeal of 'leader' or 'mentor' as a replacement for 'manager' as well as the less publicised and potent, but no less pervasive, preference of the managed to substitute other categories (e.g. 'wanker', 'asshole' and 'bullshitter').

If our analysis and proposal are accepted, this does not necessarily imply or demand abandonment of themes prized by $\mathrm{CR}$ studies of management and organisations. To the contrary, attentiveness to the epistemic dimension of social reality can inform analysis of topics typically studied by CR scholars: the re/production of social structures; the variety of social mechanisms; the existence and persistence of mechanisms that perpetuate a questionable (self) understanding of agents and so on. A significant consequence of reinstating epistemological relativism at the heart of critical realism, however, is that CR's ontological claims must be acknowledged as fallible and provisional though, perhaps, more compelling than many alternatives.

\section{Implications for meta-theoretical and methodological CR studies}


Reinstating epistemological relativism problematizes any inclination to dismiss a specific theory or methodology solely on the basis that it assumes a different ontology. In this respect, we agree with Fleetwood (2005) that 'having the "right" ontology does not guarantee that the ensuing meta-theory, theory and practice will also be "right". We are more dubious, however, about his assertion that "having the "wrong" ontology makes this virtually impossible - although we might be right by accident' (Fleetwood 2005: 198). Our point is not that ontology is irrelevant or unimportant but that disagreements about ontological claims do not warrant the categorical dismissal of substantive statements. Taking epistemological relativism seriously would, in our view, caution against basing assessments of knowledgeclaims upon such a test of their (projected) ontological credentials. For instance, Max Weber's writings may exhibit traces of an actualist ontology which assumes implicitly that reality is composed exclusively of observable events. In terms of CR ontology, Weber's ontology conflates the domains of the phenomenal, of the actual and of the real. In our view, this does not warrant dismissal of Weber's contribution, although it may helpfully prompt identification of specific limitations, contradictions or conceptual slidings in his work - such as his substitution of 'domination by virtue of a constellation of interests' (Weber 1978/1922: 943 ) in favour of the more readily observable 'domination by virtue of authority' (Weber 1978/1922: 946). Here we gesture towards the possibility of an informed pluralism (Willmott 2008) that accommodates diverse epistemic cultures and associated bodies of knowledge that are not judged on the basis of their approximation to the 'right ontology' but, rather, upon a (necessarily contested) evaluation of their congruence and assistance with the realization of diverse, favoured value-orientations. In sum, a fuller embrace of epistemological relativism cautions against invoking other elements of CR metatheory, including its stratified ontology, to dismiss alternative theories and associated methodologies. What, then, of the capacity of, 
and prospects for, CR's fuller embrace of epistemological relativism? In the next section, we outline two possible assessments - optimistic and sceptical

\section{Reclaiming Epistemological Relativism: Sceptical and Optimistic Assessments}

Optimistic and sceptical assessments of the prospects of CR analysis more fully embracing its espoused epistemological relativism are in agreement on a number of its key understandings. First, if knowledge, including what is conceived or recognised to be 'scientific', is a social product, then any claim to acontextual authority invites problematization. Second, there is value in drawing a distinction between the object of knowledge (e.g. 'nature' or 'society'), and whatever knowledge is (socially) produced. As the production of knowledge of objects is understood to play a constitutive role in the (re)production of the objects of such knowledge, this distinction is self-consciously heuristic. What is identified as an object of study is mediated by knowledge; and that knowledge can feed back to become constitutive of what one aspires to know. Third, there is a concern to resist any tendency to evaluate knowledge claims against a theory-independent conception of the object of study. Fourth, even if it is accepted that the objects of our theories have powers which exist independently of their identification, the very differentiation between an (intransitive) object and its powers or between the object and our knowledge of it, is held, in both 'optimistic' and 'sceptical' assessments, to be a discursive act. 


\section{A Sceptical Reading of CR}

A sceptical position arises from a difficulty in reconciling, on the one hand, CR's 'depth ontology' and the associated claim to retroductively identify generative mechanisms with, on the other, an epistemological relativism that underscores the historically contingent and fallible character of its knowledge claims (see Chouliaraki 2002). Knowledge of this depth, in the form of 'ontological realism', is invoked as a basis for warranting CR knowledge. It is also what supports CR's subscription to judgemental rationality as 'the notion of stratification is already necessary to sustain the idea of critique' (Bhaskar 1999). It is this claim to know, and capacity to disclose, the 'real' (as differentiated from the 'empirical' and the 'actual') that distinguishes CR from what its proponents describe as superficial, unscientific or 'irreal' (Joseph and Roberts, 2004a) forms of analysis. As Bhaskar (Bhaskar 1998a: xvii) puts it, 'theoretical explanation proceeds by description of significant features, retroduction to possible causes, elimination of alternatives and identification of the generative mechanism or causal structure at work'. The 'depth ontology' is what gives CR its critical edge, or epistemological advantage, vis à vis other forms of analysis which, being confined to the strata of the 'empirical' and the 'actual', are judged to be limited and, in this sense, misleading or false.

Our earlier discussion emphasised how subscription to epistemological relativism demands attentiveness to the discursive mediation of knowledge production. It means taking seriously the understanding that representations, including those of ontology, are 'produced in a manner that is conditioned by our socio-cultural (or biological or physical) determinations' (Lawson, 2003: 162, cited earlier) so that such 'determinations' (e.g. gender) are conceived to enable and also to impede what passes for knowledge (and science). The embrace of 
epistemological relativism recalls that the production and assessment of such claims is necessarily accomplished within particular discourses whose credibility is derived from, and limited by, specific power/knowledge relations. Hence the importance of discourse (cf supra section 2) and, more specifically, the understanding that CR's reference to the 'intransitive' is an articulation of a particular (CR) discourse (cf Laclau, 2002) - a discourse whose authority is conceived to be contingent upon the relations of power through which its production is accomplished and its credibility is warranted (see Chouliaraki 2002: 97 and note 10).

Despite its espousal of epistemological relativism, CR is reluctant, and perhaps constitutively unable, to acknowledge that the key distinction between 'being' and 'knowledge of being', and everything that flows from it, is the articulation of a particular discourse located historically and culturally within a specific complex of power/knowledge relations. What, in short, is missing from CR is 'some explanation of how we can be historically, ideologically and discursively located beings and yet still be able to make foundational truth claims' (O'Regan 2005: 577). In response, advocates of CR may berate critics for overlooking its endorsement of epistemological relativism but this defence is not easily reconciled with CR's routine trumping of its capacity to know and disclose the 'real'. Nor is it readily reconciled with the routine relegation of epistemological relativism to a secondary role (cf. Woolgar and Pawluch 1985: esp 217, 224) where it is invoked post hoc to note how, in common with all truth claims, $\mathrm{CR}$ is fallible. Acknowledgment of epistemological relativism then amounts to little more than lip service to a stance that, in practice, is mobilised to brush off its critics. Were epistemological relativism to be granted a status equivalent to ontological realism, it would recall the radical contingency of CR's 
foundational assumptions - a concession that would also prompt the search for an alternative justification of its subscription to judgemental rationality.

Adherence to a sceptical position does not mean that 'a search for grounds for determining whether some representations constitute better knowledge of the world than others' is abandoned (Fairclough 2005: 922). But it does involve problematizing what is counted, or naturalized, as 'better' ${ }^{\text {, vii }}$. The adoption of a sceptical posture does not mean that there is no basis for challenging knowledge claims, and, therefore, no possibility of a critical (social) science. Rather, there is an appreciation of how the production of such science is historically and culturally conditioned - for example, within gendered relations of power (e.g. Alcoff and Potter 1993); and that the 'demystificator role' attributed to science by critical realists (e.g. Bhaskar in Buch-Hansen 2005: 63) is more contingent and modest than one which assumes the capacity to detect 'false beliefs' (Bhaskar in Buch-Hansen 2005: 63) viii .

A sceptical, post-foundational stance (see Marchart 2007: esp. 14-15) invites a reconstruction of $\mathrm{CR}$ in which its 'depth ontology' is not regarded as a (foundational) necessity for scientific activity but, rather, as an articulation of a particular, historico-cultural discourse whose credibility is vested in a particular complex of power/knowledge relations. If it is not to perpetrate what it strives to discredit, CR must become more consistently reflexive in applying the strictures of epistemological relativism to its own claims. Instead of regarding $\mathrm{CR}$ as the means of accessing the real, it is more coherent to represent $\mathrm{CR}$ as 'one of the possibilities for discursively constructing the real' (Laclau 2002 in Bhaskar 2002: 84). More specifically, a key challenge for $\mathrm{CR}$ is to incorporate a full recognition of the contingent, discursively produced character of what is characterized as the intransitive dimension of (social) science. 
An Optimistic Reading of CR

A more optimistic assessment conceives of $\mathrm{CR}$ as an ongoing project, rather than as a fixed canon, in which its distinctive formulation of the distinction between transitive and intransitive dimensions is retained while incorporating an appreciation of the discursive nature of the claims articulated by both researchers and their subjects. In this way, CR comes to recognize itself more fully as a discourse - a development that is, arguably, consistent with an espoused concern to avoid the naturalization of the concepts that it uses. This optimistic view understands such a direction of development to be congruent with CR's epistemological relativism (in the strong sense); and it is reconciled with the attribution of 'deep structure' to generative mechanisms through a self-consciously discursive move.

Combining epistemological relativism with ontological realism requires $\mathrm{CR}$ to affirm its self-understanding as a discourse, including its logics of reference (Bhaskar and Laclau 2002: cf. section 2, supra). This self-understanding supposes a recognition of the social production of references employed to express referents that may or may not be socially produced and that may or may not be of a conceptual nature. In this regard, criticisms voiced by Burkitt (1999), King (1999a; 1999b) and others (cf. supra) lend weight to the assessment that CR authors have yet to insist more clearly on the centrality of epistemological relativism and, relatedly, have not fully articulated epistemological relativism with the realist logic of reference. An appreciation of epistemological relativism, as we have argued, is critical for grasping how the distinction between the transitive and intransitive dimensions is a distinction between reference and referent. When the grasp of this connection is weak or displaced, the distinction is mistakenly understood as one between agency-dependent and agency-independent features of the world. 
Reinstating the importance of epistemological relativism while maintaining the realist logics of reference has implications for social theorists as well as for researchers in organization studies. It reminds social theorists that the retroductive judgments, on which CR's ontology is based, express (compelling) possibilities rather than necessities. A close reading of the works of prominent figures of $\mathrm{CR}$, such as Bhaskar and Lawson, indicates that they do not found their ontological claims on arguments of authority but instead take as points of departure their identified intellectual contenders are willing to share. Thus, Bhaskar (1978) starts from the possibility of experiments dear to positivist scientists while Lawson (1997; 2003a) starts from people's ability to navigate in the social world, a key assumption of mainstream economics. The foundations of $\mathrm{CR}$ are therefore doubly contingent: relatively to the starting point and also to the retroductive argument that moves from the starting point to a hypothetical condition of possibility. In this perspective, the ontological claims of CR retain their usefulness for suggesting possible amendments to alternative theories (cf. analysis of Weber's theorising of domination, supra); and retroduction offers a powerful, if limited, method for exploring the social conditions of human activity. In each case, CR social theorists are of course dependent upon the acquiescence of their interlocutors/adversaries whenever they endeavour to establish their claims.

For researchers in organisation studies, remembering epistemological relativism paves the way to critical realist studies of sense-making that recognise the effects of the concepts employed by participants while acknowledging the dependence of their knowledge upon conditions which are not of their making. On this optimistic view of CR, it is not necessary to abandon the realist 'logics of the referent' (Bhaskar and Laclau 2002) in order to appreciate that much insight may be gained by problematizing the categories used by participants and researchers (which involves dereifying them and deconstructing the 
discourses in which they are articulated); and analysing the power effects of participants' categories on those practices which they are meant to describe.

Although the methods of analysis sketched earlier are not radically new in themselves, they have been widely regarded by CR scholars of MOS as typically and perhaps irredeemably associated with idealist meta-theories (Reed 2005b; Reed 2005a). Conversely, researchers favouring these methods of analysis have assumed that they could not be employed in a realist framework because of an assumed opposition of critical (ontological) realism and constructionist (epistemological) relativism (cf. Introduction). An implication of challenging this view is that the range of methods permitted by the meta-theoretical stance of CR is perhaps larger than commonly believed - a conclusion that endorses Reed's (2005b) assessment (see also supra). Furthermore, its implication for researchers interested in the formation of discursive categories is that their favoured techniques of analysis do not themselves warrant rejection of a realist ontology. This stratagem is optimistic inasmuch that it commends the retention of CR, yet it demands a self-understanding and associated form of analysis that differs from that currently advanced by many who espouse CR within MOS. A condition of the revitalized development of CR is a shift in its self-understanding - a shift that, from the sceptical standpoint outlined above, is seen to involve a radical questioning of CR's critical credentials.

\section{Conclusion}

Epistemological relativism is widely associated with constructionism but it is also a central component of critical realism (CR). The question of the compatibility of epistemological realism with its other core elements - of ontological realism and judgemental rationality - has rarely been voiced, and so it has been underexplored. Our purpose has been, first, to debunk the widespread belief that epistemological relativism is exclusive to varieties 
of constructionism; second, to stimulate reflection upon how epistemological relativism sits within CR; and, third, to sketch some possible implications for CR-aligned forms of analysis, especially in the field of management and organization studies (MOS).

We have conceived of CR as a discourse whose appeal, in the light of its subscription to epistemological relativism, is plausibly related to its resonance with currently dominant historico-cultural understandings. Epistemological relativism was found to be a core assumption of $\mathrm{CR}$ which articulates the understanding that knowledge is not only fallible but that its context-dependent production and credibility is embedded in social and political processes. When CR is engaged by MOS scholars, however, its epistemological relativism is either ignored, overlooked or reduced to fallibilism. An outcome of the marginalization of epistemological relativism is unbridled enthusiasm for making authoritative claims about the 'real' and its generative mechanisms. In triumphalist mode, the critical potency of CR appears to be significantly enhanced. Yet, arguably, the critical credentials of CR analysis are compromised - as when, for example, a concept of structure as a social relation assumes the status of a 'metaphysical entity' (King 1999a: 223) ; or, more generally, when in the name of demystification and emancipation (e.g. Buch-Hansen 2005: 63), an imperialistic ethos of closure supplants one of pluralistic openness.

Sceptics are inclined to regard the marginalizing of epistemological relativism within CR studies of management and organization as no accident. For them, its full incorporation threatens to derail the authority claimed for the CR project. Scepticism begs the question: can ontological realism and judgemental rationality be squared with epistemological relativism? For optimists, who believe that it can be squared, the challenge is show how, methodologically, CR-aligned studies may proceed when the centrality of epistemological 32 
relativism is fully embraced and incorporated. Keeping faith with the ontology of CR, they urge incorporation of epistemological relativism as a way of escaping the 'dozy bask' (Bhaskar 1986: 284 and supra) associated with the naturalization of concepts. For optimists, a central question is: which 'theoretical perspective or body of social theorizing' (Reed 2005b: 1638) and related methodologies are congruent with avoiding the naturalization of the concepts and fostering critical awareness of the political effects? The ambition of CR is preserved while capitalising upon the historical-cultural situatedness of this ambition and its associated preconceptions.

Might the optimistic and sceptical assessments be complementary rather than mutually exclusive? By keeping faith with CR's embrace of judgemental rationality, the optimistic view is inclined to exclude such a possibility. It encourages social science that is attentive to the social conditions and political effects of its assumptions but it also maintains that relations between proponents of alternative theories are of "conflict rather than merely difference' (Bhaskar 1998a: xi) with regard to the nature and explanation of the (intransitive) 'objects' of study. The optimistic stance views some accounts of the world (in the transitive dimension) as better suited than others to capture its reality (the intransitive dimension); and affirms that CR incorporates 'judgemental rationality' that can help adjudicating between competing accounts. The sceptical stance regards the transitive-intransitive distinction as one, critical, expression of the transitive. It doubts the possibility of establishing or identifying agreed, trans-theoretical, criteria for assessing different theories and their associated bodies of knowledge. Nonetheless, it allows that different approaches, including CR, can be of value so long as they incorporate and cultivate an awareness of their contingency and limitations (Ezzamel and Willmott 2008). Which of these stances prevails will depend, at least in part, on evaluations of whether the implications of epistemological relativism, as sketched earlier, can 
be addressed without becoming unrecognizable, and/or unacceptable, to current and prospective proponents of CR. 
Appendix: Number of papers mentioning "critical realism" in title, abstract or keywords of journals referenced in Business Source Complete

\begin{tabular}{|c|c|c|c|}
\hline Year & $\begin{array}{l}\text { Number of papers with } \\
\text { "CR" in title or abstract }\end{array}$ & Artefacts & $\begin{array}{l}\text { Papers dealing with } \\
\text { CR }\end{array}$ \\
\hline 2006 & 27 & 2 & 25 \\
\hline 2005 & 19 & 0 & 19 \\
\hline 2004 & 14 & 0 & 14 \\
\hline 2003 & 9 & 2 & 7 \\
\hline 2002 & 25 & 1 & 24 \\
\hline 2001 & 12 & & 12 \\
\hline 2000 & 7 & 1 & 6 \\
\hline 1999 & 10 & & 10 \\
\hline 1998 & 3 & & 3 \\
\hline 1997 & 3 & 1 & 2 \\
\hline 1996 & 7 & & 7 \\
\hline 1995 & 0 & & 0 \\
\hline 1994 & 2 & & 2 \\
\hline 1993 & 2 & & 2 \\
\hline 1992 & 1 & & 1 \\
\hline 1991 & 0 & & 0 \\
\hline 1990 & 2 & & 2 \\
\hline
\end{tabular}

Total 


\section{References}

Ackroyd, S. and S. Fleetwood, Eds. (2000). Realist perspectives on management and organisations. Critical realism-interventions. London ; New York, Routledge.

Al-Amoudi, I. (2007). "Redrawing Foucault's social ontology." Organization 14(4): 543-563.

Alcoff, L. and E. Potter (1993). "Feminist Epistemologies, Routledge." New York.

Archer, M. S. (2000). "For structure: its reality, properties and powers: A reply to Anthony King." The Sociological Review 48(3): 464-472.

Archer, M. S., R. Bhaskar, et al., Eds. (1998). Critical realism : essential readings. Critical realism--interventions. London, Routledge.

Bhaskar, R. (1978). A realist theory of science. Hassocks, Sussex Atlantic Highlands, N.J., Harvester Press ; Humanities Press.

Bhaskar, R. (1986). Scientific realism and human emancipation. London, Verso.

Bhaskar, R. (1989). Reclaiming reality : a critical introduction to contemporary philosophy. London, Verso.

Bhaskar, R. (1998a). General introduction. Critical realism : essential readings. M. S. Archer, R. Bhaskar, A. Collier, T. Lawson and A. Norrie. London, Routledge: ix-xxiv.

Bhaskar, R. (1998b). Philosophy and scientific realism. Critical realism : essential readings. M. S. Archer, R. Bhaskar, A. Collier, T. Lawson and A. Norrie. London, Routledge: 16-47. 
Bhaskar, R. (1998/1979). The possibility of naturalism: A philosophical critique of the contemporary human sciences. London; New York, Routledge.

Bhaskar, R. (1999). "Roy Bhaskar Interviewed." The Philosophers' Magazine, from http://www.raggedclaws.com/criticalrealism/archive/rbhaskar_rbi.html, last accessed 23 Sep 2009.

Bhaskar, R., Ed. (2002). From Science to Emancipation: Alienation and the Actuality of Enlightenment. London, Sage.

Bhaskar, R. and E. Laclau (2002). 'Critical Realism and Discourse Theory: Debate with Ernesto Laclau'. From Science to Emancipation: Alienation and the Actuality of Enlightenment. R. Bhaskar. London, Sage.

Buch-Hansen, H. (2005). "Critical Realism in the Social Sciences: An Interview with Roy Bhaskar." Distinktion(11): 59-69.

Burkitt, I. (1999). Bodies of thought : embodiment, identity, and modernity. London ; Thousand Oaks, Calif., Sage Publications.

Chouliaraki, L. (2002). "The Contingency of Universality : Some Thoughts on Discourse and Realism." Social semiotics 12(1): 83-114.

Coopey, J., O. Keegan, et al. (2000). Managers' Innovations and the Structuration of Innovations. Realist perspectives on management and organisations. S. Ackroyd and S. Fleetwood. London ; New York, Routledge: 181-204. 
Costello, N. (2000). Routines, Strategy and Change in High Technology Small Firms. Realist perspectives on management and organisations. S. Ackroyd and S. Fleetwood. London ; New York, Routledge: 161-180.

Delbridge, R. (2004). Working in teams: ethnographic evidence from two 'high performance'

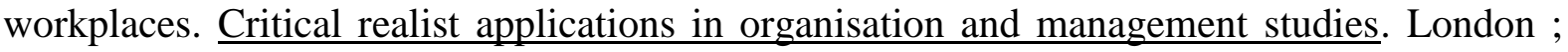
New York, Routledge: 257-273.

Dreyfus, H. L. and P. Rabinow (1982). Michel Foucault: Beyond structuralism and hermeneutics. Brighton, Harvester.

Easton, G. (2000). Case research as a method for industrial networks: a realist apologia. Realist perspectives on management and organisations. S. Ackroyd and S. Fleetwood. London ; New York, Routledge: 205-219.

Edward, P. and H. Willmott (2008). Structures, identities and politics: bringing corporate citizenship into the corporation. Handbook of research on global corporate citizenship. $\mathrm{G}$. Palazzo and A. Scherer. Northampton, MA, Edward Elgar: 405-429.

Edwards, D., M. Ashmore, et al. (1995). "Death and Furniture: the rhetoric, politics and theology of bottom line arguments against relativism." History of the Human Sciences $8(2)$ : $25-49$.

Ezzamel, M. and H. Willmott (2008). "Strategy as Discourse in a Global Retailer: A Supplement to Rationalist and Interpretivist Accounts." Organization Studies 29(2): 191-218.

Fairclough, N. (1995). Critical discourse analysis: The critical study of language. London, Longman. 
Fairclough, N. (2005). "Discourse Analysis in Organization Studies: The Case for Critical Realism." Organization Studies (01708406) 26(6): 915-939.

Fairclough, N., B. Jessop, et al. (2002). "Critical realism and semiosis." Journal of Critical Realism 5(1): 2-10.

Fleetwood, S. (2004). An ontology for organisation and management studies. Critical realist applications in organisation and management studies. S. Fleetwood and S. Ackroyd. London ; New York, Routledge: 27-54.

Fleetwood, S. (2005). "Ontology in organization and management studies: A critical realist perspective." Organization 12: 197-222.

Fleetwood, S. and S. Ackroyd (2004). Critical realist applications in organisation and management studies. London ; New York, Routledge.

Foucault, M. (1970). "The Discourse on Language" in The Archaeology of Knowledge. New York, Pantheon Books, N. Y, 1972. First published as L'Ordre du discours, Gallimard, Paris, 1971.

Foucault, M. (1972). The archaeology of knowledge. London, Tavistock Publications.

Foucault, M. (1977). Discipline and punish: The birth of the prison. New York, Pantheon Books.

Foucault, M. (1978). The history of sexuality. New York, Pantheon.

Gergen, K. (1998). Constructionism and realism: How are we to go on? Social Constructionism, Discourse, and Realism. I. Parker. London ; Thousand Oaks, Calif., Sage Publications: xii, 159 p. 
Hesketh, A. and P. Brown (2004). I say tomato, you say tamato: puuting critical realism to work in the knowledge worker recruitment process. Critical realist applications in organisation and management studies. London ; New York, Routledge: 337-356.

Joseph, J. (2004). "Foucault and reality." Capital \& Class(82): 143-165.

Kennedy, C. and P. Kennedy (2004). The moral management of nursing labour power: conceptualising control and resistance. Critical realist applications in organisation and management studies. London ; New York, Routledge: 321-336.

King, A. (1999a). "Against Structure: A Critique of Morphogenetic Social Theory." The Sociological Review 47(2): 199-227.

King, A. (1999b). "The impossibility of naturalism: The antinomies of Bhaskar's realism." Journal for the Theory of Social Behaviour 29(3): 267-288.

Kowalczyk, R. (2004). Tracing the effects of a hospital merger. Critical realist applications in organisation and management studies. London ; New York, Routledge: 298-320.

Kwan, K.-M. and E. W. K. Tsang (2001). "Realism and Constructivism in Strategy Research: a Critical Realist Response to Mir and Watson." Strategic Management Journal 22(12): 1163.

Laclau, E. and C. Mouffe (1985). Hegemony and socialist strategy: Towards a radical democratic politics. London, Verso.

Lawson, T. (1997). Economics and reality. London ; New York, Routledge.

Lawson, T. (1998). Critical Issues in Economics as Realist Social Theory. Critical Realism in Economics. S. Fleetwood, Routledge: 209-257. 
Lawson, T. (2003a). Reorienting economics. London, Routledge.

Lawson, T. (2003b). "Theorizing Ontology." Feminist Economics 9(1): 161.

Marchart, O. (2007). Post-foundational political thought: political difference in Nancy, Lefort, Badiou and Laclau, Edinburgh Univ Pr.

Marsden, R. (1999). The nature of capital: Marx after Foucault. London ; New York, Routledge.

Mir, R. and A. Watson (2000). "Strategic Management and the Philosophy Of Science: the Case for a Constructivist Methodology." Strategic Management Journal 21(9): 941.

Mir, R. and A. Watson (2001). "Critical Realism and Constructivism in Strategy Research: Toward a Synthesis." Strategic Management Journal 22(12): 1169.

Mutch, A. (2007). "Reflexivity and the Institutional Entrepreneur: A Historical Exploration." Organization Studies (01708406) 28(7): 1123-1140.

Mutch, A., R. Delbridge, et al. (2006). "Situating Organizational Action: The Relational Sociology of Organizations." Organization 13(5): 607-625.

Newton, T. (2007). Nature and sociology. Milton Park, Abingdon, Oxon ; New York, Routledge.

O'Regan, J. P. (2005). "Discourse, Domination, and What it Means to be Critical: the "Disciplining" of Foucault's Perception of Power in Critical Discourse Analysis'." Proceedings of the International Conference on Critical Discourse Analysis: Theory into Research, University of Tasmania, from 
http://www.educ.utas.edu.au/conference/Files/proceedings/cda-proceedings-p5.pdf Accessed 22 September 2009.

Parker, I. (1998). Social Constructionism, Discourse, and Realism. London ; Thousand Oaks, Calif., Sage Publications.

Peck, J. (2000). Structuring the labour market: a segmentation approach. Realist perspectives on management and organisations. S. Ackroyd and S. Fleetwood. London ; New York, Routledge: 220-244.

Phillips, N., T. B. Lawrence, et al. (2006). "Discussing "Discourse and Institutions": A Reply to Lok and Willmott." Academy of Management Review 31(2): 480-483.

Porter, S. (2000). Critical Realist Ethnography: the Case of Racism and Professionalism in a Medical Setting. Realist perspectives on management and organisations. S. Ackroyd and S. Fleetwood. London ; New York, Routledge: 141-160.

Reed, M. (2005a). "Doing the loco-motion: Response to Contu and Willmott's commentary on 'the realist Turn in organization and management studies'." Journal of Management Studies 42(8): 1663-1673.

Reed, M. (2005b). "Reflections on the 'realist turn' in organization and management studies." Journal of Management Studies 42(8): 1621-1644.

Rubery, J. (2000). The British production regime: a societal-specific system? Realist perspectives on management and organisations. S. Ackroyd and S. Fleetwood. London ; New York, Routledge: 245-264.

Sayer, A. (2000). Realism and social science. London, SAGE. 
Sayer, A. (2005). The Moral Signification of Class. Cambridge, UK, Cambridge University Press.

Schwandt, T. A. (2000). Three epistemological stances for qualitative inquiry: Interpretitivism, Hermeneutics and Social Constructivism. Handbook of qualitative research. N. K. Denzin and Y. S. Lincoln. Thousand Oaks, Sage. 2: 189-213.

Taylor, P. and P. Bain (2004). Humour and Subversion in Two Call Centres. Critical realist applications in organisation and management studies. London ; New York, Routledge: 274297.

Tsoukas, H. (1994). "What is Management? An Outline of a Metatheory." British Journal of Management 5(4): 289.

Van Maanen, J. (1995). "Crossroads. Style as theory." Organization Science 6(1): 132.

Weber, M. (1978/1922). Economy and society: An outline of interpretive sociology. Berkeley, University of California Press.

Willmott, H. (1996). "A Metatheory of Management: Omniscience or Obfuscation? A Comment 1." British Journal of Management 7(4): 323-327.

Willmott, H. (2008). "For Informed Pluralism, Broad Relevance and Critical Reflexivity." The SAGE handbook of new approaches in management and organization: 82 .

Woolgar, S. and D. Pawluch (1985). "Ontological gerrymandering: The anatomy of social problems explanations." Social Problems: 214-227. 
i We are grateful for comments from Roy Bhaskar, John Hendry, Clive and Tony Lawson, Raza Mir and Andrew Sayer as well as members of the Cambridge Realist Workshop on earlier versions of this paper. During the editorial stages, Tim Newton and three anonymous referees have also provided generous comments. The usual disclaimers apply.

ii Although the terms 'constructivism' and 'constructionism' are widely used in an interchangeable manner, Phillips, Lawrence and Hardy have suggested that constructivism has its origins in Piaget's developmental psychology where the notion of people as active constructors, rather than passive receptors, of knowledge is emphasized. From this perspective “'“reality”... is constructed in people's minds' (Phillips, Lawrence et al. 2006: $480, \mathrm{n} 1)$. Social constructionism is understood to "build on these ideas but emphasizes the social nature of reality - it is not constructed merely in people's minds but in their social interaction, and especially in their linguistic interaction because of the enduring traces that this form of interaction is particularly capable of producing' (ibid). For another reflection on this difference, see Schwandt (2000: esp. 208).

iii CR writings allude sometimes to 'epistemic relativism' and sometimes to 'epistemological relativism'. Sayer distinguishes them on the basis that epistemological relativism 'implies that it is philosophical theories of knowledge that mediate our understanding, whereas [epistemic relativism] just implies existing knowledge or discourse does the mediating' (personal communication). Other authors, such as Tony Lawson use them interchangeably (personal communication). 
${ }^{i v}$ It is certainly not our intention to cast Laclau as the legitimate voice of critical MOS. We have chosen to oppose CR with the works of Laclau because we felt the latter are particularly attentive to the conditions, processes and effects of knowledge production. Moreover, we found valuable sources in the recorded debate between Bhaskar and Laclau as well as in Reed's (2005b; Reed 2005a) paper that suggests that CR is fundamentally opposed to all forms of postmodernism and post-structuralism.

${ }^{\mathrm{v}}$ We do not include the contributions of Peck and Rubery (in Ackroyd and Fleetwood 2000) as these do not claim critical realist credentials. Our remarks about the absence of ER are maintained a fortiori for these pieces.

${ }^{v i}$ These practices are non-discursive in the sense Foucault assigns to discourse. Under an alternative conception such as Laclau and Mouffe's, all the practices and entities enumerated herein would be considered as discursive (Laclau and Mouffe 1985)

vii On this issue, it is relevant to note that CR's defence of its privileging of "ontological realism' is at least partially an ethical one (see Bhaskar 1989: 5-6), or an 'irreducibly normative activity' (Bhaskar, 1989: 159). We have noted how the potency of CR knowledge is most overtly articulated, in a rather scientistic and also somewhat circular manner, by reference to its ' depth ontology'. But CR is also, and perhaps ultimately, justified in the name of judgemental rationality - albeit that CR conceives of forms of 'agreement' amongst 'peers' as having a 'descriptive or evidential', in addition to a 'prescriptive, imperatival' component that is subjected to CR scrutiny in order to yield 'ontologically grounded, or justified, scientific explanation(s)'. 
viii Advocates of CR have argued that such criticisms fail to distinguish between 'being' and 'knowledge of being' and therefore slide into 'judgemental relativism' where all representations of the world are taken to be equally good (see Fairclough 2005: 922). This criticism is predicated upon a reluctance to recognize the embeddedness of all representations, including those of $\mathrm{CR}$, within power/knowledge relations. From a sceptical standpoint, the (transitive) claims about the intransitive are necessarily constrained as well as enabled by established, hegemonic conceptions of their status and relationship. For anyone committed to critique, the challenge is to question and subvert forms of knowledge that aspire, or claim, to place closure on our accounts with, and of, reality. 